\title{
Contextual Prejudice: How Occupational Context and Stereotypes Shape Bias against Gay and Lesbian Employees
}

\author{
Emma Mishel $^{1}$ \\ New York University
}

Forthcoming in Social Currents

\begin{abstract}
:
While much research provides evidence that gay men and lesbians are discriminated against in the U.S. labor force, the contexts in which such bias is enhanced or reduced, or the mechanisms behind it, are harder to pinpoint. This article puts forth that occupational context-and specifically, the stereotypes about gay men and lesbians evoked by certain occupational contexts - play an important role in shaping bias against gay men and lesbians in the labor force. I argue that people are implicitly guided by cultural stereotypes about gay men and lesbians, which affects perceptions about whether they are suitable for specific occupations. This leads to penalties for being openly gay or lesbian in some occupational scenarios, but may lead to less or no penalties in others. This theory is tested empirically using a list experiment, a methodological technique designed to reduce or eliminate social desirability bias in responses. Results suggest that bias against gay men and lesbians is not standard across all occupations or subgroups of gay employees, but rather, is shaped by important contextual factors that can activate certain stereotypes about gay and lesbian individuals.
\end{abstract}

\section{INTRODUCTION}

Social scientists have long attempted to assess whether specific outgroups are victims of bias, to examine the contexts in which bias occurs, and to explore the possible mechanisms driving bias. For example, in examining bias against women, Ridgeway and Correll (2004) argue that when gender is salient in social-relational contexts, cultural beliefs about gender - such as

${ }^{1}$ Correspondence concerning this article should be addressed to Emma Mishel, NYU Department of Sociology, Puck Building, 295 Lafayette Street, 4th Floor, New York, NY 10012-9605; email: emmamishel@nyu.edu. 
that men are more competent than women at most things - bias evaluations of otherwise similar men and women. Furthermore, when examining racial bias, some researchers focus on the effects of social context, such as percent black in a neighborhood, to examine perceptions and experiences of racism (Hunt et al. 2007). Less has been explored about the social contexts in which anti-gay bias occurs, is accentuated or reduced, or about the mechanisms surrounding antigay bias, particularly when examining bias against gay men and lesbians in the U.S. labor force. Most research on labor market discrimination against gay men and lesbians find evidence that they are discriminated against in both hiring and wages (e.g., Elmslie and Tebaldi 2007; Baumle and Poston 2011; Tilcsik 2011; Mishel 2016). Some studies have tried to ascertain how certain factors shape discrimination, in attempts to identify potential mechanisms of bias against gay and lesbian employees. For example, researchers have looked at how anti-discrimination laws, race, geographic location, family arrangements, and cultural and interactional factors, influence labor market discrimination against gay men and lesbians (e.g., Baumle and Poston 2011; Tilcsik 2011; Pedulla 2014; Mize 2016; Denissen and Saguy 2014; Compton and Dougherty 2017). One mechanism that, I argue, plays a vital role in shaping bias against gay and lesbian employees but that has received less attention, is occupational context, and specifically, the stereotypes about gay people that certain occupational contexts may evoke.

Of previous quantitative studies that assess causal evidence of employment discrimination based on sexual orientation in the U.S., only two studies assess the role of stereotypes. First, in his résumé audit study on hiring discrimination against gay men, Tilcsik (2011) found that gay men were significantly less likely to be invited for an interview compared to straight men for positions where employers emphasized stereotypically "masculine" traits in the job ad (i.e., looking for an "aggressive leader"). Tilcsik concludes that at least part of the 
anti-gay discrimination found can be attributed to employers' stereotyping of gay men as not masculine or aggressive (2011). Second, in his experimental study asking respondents to suggest salary recommendations for fictitious gay, straight, white, and black men, Pedulla (2014) found that gay black men were given the highest salary recommendations, which he attributes to multiple counteracting stereotypes. Specifically, he argues that negative stereotypes of black men as threatening and criminal counteract negative stereotypes of gay men as effeminate and weak, resulting in positive consequences for black men who are gay. However, both Tilcsik's (2011) and Pedulla's (2014) experiments only explore stereotyping as a potential mechanism for employment discrimination against gay men, and they leave questions open as to how different stereotypes can influence bias in different contexts. For example, are there some occupational contexts in which stereotypes play a larger role than others? Are there occupational contexts in which the stereotypes evoked elicit an advantage rather than a penalty for the gay employee? And, do these patterns differ for lesbians and gay men?

In this study, I build on the theory that stereotyping is an important mechanism of employment discrimination based on sexual orientation. I do so by conducting an experiment that analyzes how different occupational contexts, and the potential stereotypes evoked about gay people within these contexts, shape bias against gay and lesbian employees. I posit that different occupational scenarios have the power to activate different stereotypes about gay men and lesbians, which in turn, can influence respondents' opinions about which occupations are appropriate for gay men and lesbians and which are not.

In the first section of this paper, I review some of the existing literature on mechanisms behind bias against gay and lesbian employees, including stereotypes sometimes attributed to gay individuals and the repercussions of such stereotypes on their workplace outcomes. In the 
second section, I explain my data, hypotheses, and analytical strategy of using a list experiment for this study. In the final section I present my results and discuss the findings. To preview my results, I find that respondents' bias against gay and lesbian employees varies greatly by occupational context; in some occupational contexts, bias against gay men and lesbians is greater, while in others, bias is less, or even non-existent. Results suggest that bias against gay

men and lesbians in the U.S. labor force is shaped by stereotypes about gay individuals evoked in different occupational contexts, and cannot be reduced to a general animosity towards gay and lesbian employees.

\section{MECHANISMS BEHIND BIAS AGAINST GAY AND LESBIAN EMPLOYEES}

Most studies assessing evidence of employment discrimination based on sexual

orientation in the U.S. find that gay men and lesbians are discriminated against compared to their straight counterparts in both hiring (i.e., Tilcsik 2011; Mishel 2016) and wages (e.g., Badgett 1995; Elmslie and Tebaldi 2007; Baumle and Poston 2011). Audit study designs are the gold standard in establishing causal evidence of discrimination, but they have limitations in assessing mechanisms of discrimination since they are unable to procure information on why gay applicants are invited for an interview less often than their straight counterparts (Tilcsik 2011; Mishel 2016). Similarly, wage discrimination studies control for a variety of observable factors that can influence wages, but they have difficulties identifying specific mechanisms that explain remaining differences in wages.

Despite these difficulties, researchers have sought to ascertain potential mechanisms of bias against gay men and lesbians in the labor force. For example, some have argued that sexual orientation is a diffuse status characteristic (Johnson 1995), and that lower performance expectations are attached to gay individuals compared to straight individuals, which affects their 
labor market outcomes (Webster et al. 1998). Others have focused on how the following factors influence bias against gay and lesbian employees: anti-discrimination laws and policies (e.g., Colgan et al. 2008; Baumle and Poston 2011; Tilcsik 2011; Mishel 2016); geographic location (e.g., Tilcsik 2011; Mishel 2016; Connell 2015); race (e.g., Pedulla 2014); family arrangements, such as being married or having children (e.g. Baumle and Poston 2011; Mize 2016); presence of same-sex partnerships in the locale (e.g., Baumle and Poston 2011); and cultural and interactional factors within the gay employee's work environment (e.g., Wright 2011; Denissen and Saguy 2014; Compton and Dougherty 2017). One mechanism that, I argue, plays a vital role in shaping bias against gay and lesbian employees but that has received less attention, is occupational context, and the stereotypes about gay people that occupational contexts may evoke.

Stereotypes are commonly held beliefs about a social group (Banaji 2002), while stereotyping is the process by which stereotypes are used in judgments about a social group or its members - both of which can have powerful effects on how people treat and perceive each other (Fiske 1998; Ridgeway 2009; Tilcsik 2011). As discussed above, Tilcsik (2011) and Pedulla (2014) both find that stereotyping plays a role in labor market discrimination against gay men, but questions remain regarding how different stereotypes may shape bias in different contexts, and how and whether patterns differ for gay men and lesbians. Below, I discuss some negative stereotypes that are sometimes attributed to gay men and lesbians, and the potential repercussions of such stereotypes on workplace outcomes.

Stereotypes that Gay People Are Immoral, Sexual Predators. Historically, discrimination against gay men and lesbians in the labor market has largely revolved around concerns about morality, sexual promiscuity, and protecting children. In the 1950s, for example, 
teachers were forced to sign "morality" clauses, and homosexual behavior was a direct violation of such an agreement (Connell 2015). As another example, in the late 1970s, Anita Bryant and over thirty politically conservative professionals and ministers created the "Save Our Children" campaign, of which the central message was that gay people were child molesters who were trying to "recruit our children into homosexuality" (Clendinen 1999; Fejes 2008; see also Stone 2018). Much research has debunked the myth that gay men and lesbians are child molesters (see Groth and Birnbaum 1978; Freund et al. 1989; Jenny et al. 1994), and a majority of heterosexual Americans today do not believe that most gay men and lesbians are child molesters (Herek 2002; Herek 2009). However, the stereotype continues to be invoked by pro-family organizations that are anti-gay (e.g., Family Research Institute 2006). These anti-gay organizations and their followers argue that pedophilia will occur if adult gay people are placed within short distances of, or interact with, young children - especially adult gay men around young boys (Family Research Council 2002; Knauer 2000). Not only do they put forth the notion that children are at risk of abuse if a gay person is present, but that children who are exposed to them have an increased likelihood of becoming gay themselves (Baldwin 2002; Fejes 2008; Knauer 2000).

Stereotypes that Gay People (Especially Gay Men) Have HIV/AIDS. These anti-gay groups and their followers also emphasize the HIV/AIDS epidemic in portraying gay sexespecially sex between gay men - as not only immoral, but as unhealthy and promiscuous (Knauer 2000). Associating gay people with HIV/AIDS allowed for the linking of gay individuals with illness and moral corruption, legitimating abhorrence towards gay sexual activity (Kayal 1993), and severely stunting advances in gay rights initiatives (Connell 2015).

While the stereotype has some basis, as research finds that those who have HIV/AIDS in the U.S. are disproportionately men who sleep with men (Singh et al. 2017), the epidemiology of 
AIDS in the U.S. changed considerably from the 1980s to the 1990s; for example, by 1997, only $35 \%$ of the new AIDS cases in the U.S. were diagnosed among men who reported sex with another man, and another $4 \%$ among men who reported both gay sex and injection drug use (CDC 1997, as cited in Herek 1999). As such, health education specialists and trainees sought to counter the association between AIDS and gay sex, arguing that it is an "equal opportunity" virus that can affect anyone (Kitzinger and Peel 2005). Indeed, Herek $(1991,1999)$ finds that anti-gay attitudes are strongly related to misunderstandings as to how HIV/AIDS is transmitted. In fact, in a 2006 Kaiser Family Foundation survey, one third of Americans didn't know that HIV isn't spread through kissing, and one fourth didn't know it can't be spread by sharing a drinking glass (KFF 2006). In general, stereotypes of gay individuals as having HIV/AIDS could align with a conception of homophobia (defined as dislike of or bias against LGB individuals) as a medical phobia, or as a fear of contagion (Weinberg 1973).

Stereotypes that Gay People are Gender Transgressors. Another stereotype commonly attributed to gay men and lesbians relates to gender expression. In American society, gay men are often viewed as more feminine than other men, and lesbians are often viewed as more masculine than other women (Madon 1997; Ward 2008). In other words, gay men and lesbians are stereotyped as gender non-conforming, with gay men assumed to be feminine and lesbians assumed to be masculine (Giuffre et al. 2008; Mize and Manago 2018). One conception of bias against gay men and lesbians is rooted in disapproval of such gender transgressions.

Repercussions of Such Stereotypes. Previous qualitative studies show that such stereotypes can have far-reaching repercussions on the workplace experiences of gay men and lesbians. For example, Giuffre et al. (2008) find that assumptions of lesbians as "masculine" in their personalities and behaviors and gay men as "feminine" subject gay men and lesbians to 
various forms of sexism in the workplace. The supposed femininity of gay men, for example, can result in their exclusion from "masculine" activities and job assignments, resulting in similar forms of gender discrimination that women can experience (Giuffre et al. 2008). Along these lines, Williams (1992) finds that the stigma associated with being gay leads some men to exaggerate their masculine qualities while at work. As another example, Giuffre et al. (2008) find that lesbians are sometimes subject to a unique form of sexism where straight men make sexual and vulgar comments about other women in front of them, and expect them to share in sexist attitudes because they are lesbians.

In addition, Connell (2015) finds that many gay and lesbian teachers do not come out about their non-heterosexuality in fear that students would retaliate and claim they are pedophiles; others are careful to not touch, give hugs, or give presents to their students in fear that it would be read the wrong way. In fact, Connell finds that some gay teachers experience what Williams (1992) calls the "glass escalator," where gay men are propelled from classroom instruction into administrative positions by the glass escalator due to homophobic discomfort about them working with children (Connell 2015). Indeed, in her study of men working in female-dominated occupational fields such as teaching, nursing, librarianship, and social work, Williams (1992) finds that male elementary school teachers are often confronted by suspicions that they are pedophiles, and that men in all 4 professions needed to safeguard against suspicions of sexual abuse, especially those who come into contact with women and children.

What's more, other studies find that the stereotype of being sexually promiscuous is especially damaging to gay men in professional settings (Williams and Giuffre 2011; Rumens and Kerfoot 2009), and that the stereotype of gay individuals having HIV/AIDS (or any sexually transmitted infection in general) leads to slut-shaming and stigma against gay men, even among 
gay men themselves (Orzechowicz 2016). Indeed, even in gay-friendly workplaces—meaning, organizations where sexual minorities people feel accepted (see Giuffre et al. 2008) - Williams et al. find that gay men required constant negotiation of the stereotype that they were "skanky" or "nasty" (2009).

Occupational Contexts and the Current State of the Workplace Closet. In the last few decades, there have been many gains in workplace rights for gay people (Williams and Giuffre 2011; Connell 2015); indeed, as of today, 22 states and D.C. have passed legislation explicitly protecting individuals from workplace discrimination based on sexual orientation (Movement Advancement Project 2019). Despite this progress, many social scientists argue that the mere presence of gay and lesbian individuals in the workplace is still threatening to organizations, because it threatens the belief that to be professional, workplaces should be "asexual" (Connell 2015, Orzechowitz 2016; Rumens and Kerfoot 2009). Building off Acker's (1990) argument that institutions are inherently gendered, some social scientists have expanded on this notion to argue that organizations are inherently (hetero)sexualized, and can be homophobic.

Hearn and Parkin (1987), for example, argue that heterosexuality is institutionalized in work organizations through policies that privilege nuclear families, through interactions between coworkers and clients that stigmatize homosexuality, and through cultural norms that discourage discussions about intimate gay and lesbian relationships (cited in Giuffre et al. 2008). Along these lines, many social scientists argue that professional organizations are sexual, but they do not appear sexual because they endorse heterosexuality, the taken-for-granted form (Colgan et al. 2008; Rumens and Kerfoot 2009; Williams and Giuffre 2011). This means that straight workers can still be perceived as respectable and professional if they wear wedding rings to work, date their coworkers, display photos of their straight nuclear families, or bring their spouse 
or significant other to the office. In contrast, gay and lesbian employees are not able to engage in this same behavior without drawing attention to their (homo)sexuality, and thus, a perception that they are unprofessional (Williams and Giuffre 2011). This creates a tension between pride (being out at work) and professionalism (refraining from showing or drawing attention to their sexuality) for some gay and lesbian workers (Connell 2015; Rumens and Kerfoot 2009). Even in workplaces that gay and lesbian employees themselves label "gay-friendly," Williams et al. (2009) find that they are still faced with a choice of being "normal" (straight appearing) or being invisible (not out). Indeed, studies find that in gay-friendly workplaces, gay workers are forced to either downplay their homosexuality or they are constrained by stereotypes about how they are expected to look, act, and work (Williams et al. 2009; Rumens and Kerfoot 2009).

The current pride-versus-professionalism debate, or acceptance-versus-visibility constraint, on gay workers is directly tied to (and driven from) some of the stereotypes about gay people discussed above, such as negative beliefs that gay people are immoral/sexual predators, have HIV/AIDs, and/or behave and dress in gender-nonconforming ways. Indeed, Giuffre et al. (2008) find that although these stereotypes are rarely explicitly voiced today, these stereotypes have not gone away, and are actually surfaced in a more subtle manner. Thus, even in the current climate of increased workplace protections and "gay-friendly" workplace contexts, negative stereotypes about gay men and lesbians still abound, and have the power to elicit prejudice against gay employees. But — do such negative stereotypes about gay people play a larger role in certain occupational contexts compared to others? Are there occupational contexts in which the stereotypes evoked elicit an advantage, rather than a penalty, for the gay employee? And, do patterns differ for lesbians and gay men? These are the questions my study seeks to answer, as I posit that different occupational scenarios have the power to activate different stereotypes about 
gay men and lesbians, which in turn, can influence bias against them. In the following section, I explain my data and analytical strategy for this research.

\section{DATA AND ANALYTICAL STRATEGY}

\section{The List Experiment Technique}

To measure bias against gay men and lesbians in the labor market, I use a list experiment — a methodological technique that reduces or possibly eliminates the effect of social desirability bias in responses - or, the tendency of individuals to alter their response to a questionnaire or interview in order to be viewed in a favorable light by other people. This is vital, because the growing social acceptance of LGBT people in America (see Ford and England 2016; Lewis 2018) may pressure respondents to answer in a way that is seen as not discriminatory towards the gay community when they are asked to share their opinion about gay men and lesbians in the labor market. I focus on measuring bias against gay men and lesbians (and not bisexual or transgender individuals) due to limitations in the number of treatment statements I could reasonably include in the experiment, and due to specific stereotypes about gay men and lesbians that my list experiment seeks to activate. Stereotypes specific to bisexual and transgender individuals may differ from those discussed above.

In addition, in this study, I focus on consumer bias against gay and lesbian employeesi.e., how customers and clients who come into contact with gay and lesbian employees feel about them. While résumé audit studies have provided causal evidence of employer bias against gay men and lesbians (i.e., Mishel 2016; Tilcsik 2011), less is known about how and when consumer bias against gay and lesbian employees occurs. This is an important area to shed light upon since, in addition to the fact that consumers may insult or offend gay and lesbian employees, consumer bias can lead to employment discrimination (Flake 2016; Wang 2016). Employers are driven by 
self-interest to please customers - whose satisfaction is critical to business success. In this sense, customers play a powerful role in determining the terms, conditions, and privileges of employment for gay men and lesbians (Flake 2016; Wang 2016).

The list experiment technique was created to allow respondents to express hostility or prejudice towards something or someone without anyone being aware that they have done soin other words, to allow respondents to give an answer to a sensitive question indirectly. Originally pioneered to measure levels of racial prejudice (Kuklinski et al. 1997), researchers have successfully used list experiments (and a similar variant known as the unmatched count technique, or UCT) to study topics such as: interracial dating (Sniderman and Carmines 1997), attitudes about immigration (Janus 2010), voting bias against a black president (Heerwig and McCabe 2009), measurement of "risky" sexual behavior (LaBrie and Earleywine 2000), and estimates of women who have had an abortion (Cowan et al. 2016). In a variety of contexts, the list experiment or UCT methodology affords survey respondents an additional layer of anonymity that has been shown to elicit more truthful reports of behaviors and beliefs that may be perceived as socially undesirable, and it generally increases respondents' perception of privacy compared to other anonymous computer-aided surveys (Tourangeau and Yan 2007; Coutts and Jann 2011).

In the typical list experiment, respondents are randomly assigned to either a control or treatment group. Then, they are given a list of statements, and asked to indicate how many make them angry or upset. (Researchers can also ask respondents how many statements they disagree with, or how many statements apply to them, etc. The key is that it is always a numeric answer.) The control group is given a list of $n$ statements. The treatment group is given the same list of $n$ statements, plus an additional statement, for a total of $n+1$ statements. The additional statement 
is the sensitive item - meaning, the one that the researcher is actually interested in. Given the random assignment of respondents to one of the two groups, the assumption is that the nonsensitive (baseline $n$ ) items angered an equal number of people in both groups. Subtracting the mean number of items upsetting respondents in the control group from the analogous mean for the treatment group and multiplying by 100 provides an estimate of anger directed towards the additional, sensitive item (Kuklinski et al. 1997).

Because respondents in both groups are not asked directly whether these statements make them angry or upset, nor asked to select which statements make them angry or upset, but rather given a list of all statements and asked to indicate how many, the researcher will not know which of the statements the respondent is referring to with their answer, so the need for self-censorship is reduced or eliminated. The design of the list experiment makes it easier for respondents to offer a truthful response, even when social norms encourage them to respond in a certain way (Blair and Imai 2012).

\section{Sample}

Survey respondents residing in the U.S. who were at least 18 years old were recruited from Amazon Mechanical Turk (N=6,233). ${ }^{1}$ Amazon Mechanical Turk (MTurk) is a crowd sourcing internet marketplace where one is able to recruit individuals to be paid a small amount to respond to questionnaires online, among other tasks that can be done over the internet. Although samples from MTurk are not nationally representative, other researchers have successfully conducted list experiments using convenience samples (Coffman et al. 2017), and there is evidence that MTurk respondents display similar behavior in experiments to standard samples (Horton et al. 2010; Rand 2011). Furthermore, previous studies have shown that the 
subject population of respondents from MTurk are culturally and demographically diverse (Paolacci et al. 2010).

\section{Design of Experiment}

Upon entry to the survey, respondents were randomly assigned to either a control group, or to 1 of 14 possible treatment groups. Members of the control group were shown 4 statements and asked to report how many of the 4 statements made them "angry or upset." Members of each of the 14 treatment groups were given the same list of 4 baseline statements, plus 1 additional statement ( 1 of the 14 possible treatment items) for a total of 5 statements, and asked to report how many of the 5 statements angered or upset them.

After the control group's list experiment (which just included the 4 baseline items), they were then shown 3 of the 14 treatment conditions at random, and asked whether each one made them angry or upset, as a direct question. Asking the treatment group about the sensitive item indirectly (i.e., through the list experiment), and asking the control group about it directly (i.e., as a direct question), allows me to assess how and whether social desirability bias affected responses. See Figure 1 for an illustration of the list experiment design. Upon completion of the list experiment portion of the survey, respondents in both the control and treatment groups answered a series of demographic questions.

\section{Treatment Conditions and Hypotheses}

The treatment conditions were various statements about a gay man, a lesbian, or a straight employee in a certain occupation, performing specific duties. ${ }^{2}$ I posit that different occupational scenarios may evoke different stereotypes about gay men and lesbians, which in turn, may affect the estimate of bias against the gay or lesbian employee in that scenario. For example, negative stereotypes that gay people actively recruit others to practice gay sex (including children) may 
translate to greater bias against gays and lesbians in occupational roles where they work closely with populations seen as particularly vulnerable or impressionable, such as youth or young children. Under these notions, openly gay individuals become highly politicized subjects in employment settings (Knauer 2000). Here, I make my first hypothesis:

H1: Gay men and lesbians serving in occupational contexts where they are required to work closely with young children or adolescents will elicit more bias compared to gay men and lesbians who do not work closely with such populations.

Next, stereotypes about gay individuals having HIV/AIDS may translate to greater bias against gay men and lesbians in occupational roles where they work closely with another population seen as particularly vulnerable — sick people in the hospital. Yet, this stereotype is more often applied to gay men than to lesbians (Knauer 2000; Herek 2009). As such, I make my second hypothesis:

H2: Gay individuals, especially gay men, who serve in occupational contexts where they are required to work closely with those who are ill in a hospital will elicit more bias compared to gay individuals who do not work in such occupational contexts.

I am able to test these two hypotheses by comparing how many people say they are "angered or upset" by the following statements (in which either a gay man or lesbian is the subject, for 8 total treatment statements):

- A gay male/lesbian elementary school teacher teaching your young children, or young children in your community.

- A gay man/lesbian coaching and training a boys'/girls' high school basketball team in your community.

- A gay male/lesbian nurse treating you when you are sick in the hospital.

- A gay male/lesbian accountant doing your tax returns this year.

These four occupations were chosen as their responsibilities and clientele vary in important ways. Nurses work closely with sick patients; elementary school teachers work closely 
with small children; and high school coaches work closely with teenagers after school. In addition to working closely with sick people and youth, responsibilities for these three occupations may also involve touching these populations: nurses likely touch patients when they administer medication or when caring for them; elementary school teachers may touch their students to show support or encouragement, to get their attention, or to correct their behavior; high school basketball coaches may touch their players when providing instructions or demonstrating plays on the court, or when showing support. Because of this, these particular occupational scenarios may activate respondents' negative stereotypes about gay people, such that they are predatory, that they are immoral influences on children, and/or that they have HIV/AIDS. Accountants, on the other hand, do not work closely with such populations (sick people or youth); they simply work with financial records. Distinct from the other three occupations, touching is not expected as part of the occupational responsibilities of accountants (beyond an occasional handshake). In general, the idea of a gay or lesbian accountant is not expected to activate any particular stereotype commonly attributed to gay men and women.

Thus, using these four occupational scenarios as treatment conditions allows me to explore possible mechanisms around bias against gay men and lesbians in certain occupational contexts. For example, if gay and lesbian employees who work closely with populations thought of as particularly impressionable or vulnerable (nurses, elementary teachers, and high school coaches) elicit more bias from respondents than gay and lesbian employees who do not work with such populations (accountants), it suggests that these contextual differences in anti-gay bias result from the fact that anti-gay bias is often based, at least in part, on negative stereotypes sometimes attributed to gay individuals, such as sexual predation, immoral recruitment, or fears 
of contagion. I specify whether the subject in the occupational scenario is a gay man or lesbian in order to assess gender differences in these patterns.

Next, I examine whether there are certain occupational contexts in which the stereotypes that are relevant elicit an advantage rather than a penalty for the gay employee. For example, in general, Americans may have bias against women serving in particularly "masculine" occupations due to stereotypes that women are not equipped to work in such a field. But Americans may have less bias against lesbians working in masculine/male-dominated fields, due to stereotypes of lesbians as "butch" or "masculine," and thus a better fit for "male" jobs. This is consistent with some research that has documented that lesbians are generally more successful in entering male-dominated occupations than their heterosexual peers (Blandford 2003). Along the same lines, bias against men serving in "feminine" or female-dominated roles may be relaxed for gay men, precisely because of the stereotypes that they are "effeminate" and thus suitable for some female-typed jobs. Here, I make my third hypothesis: ${ }^{3}$

H3: Gay men and lesbians working in occupations stereotypically seen as appropriate for the other sex will elicit less bias compared to straight men and women working in these same occupations.

I test this hypothesis by comparing estimates of anger against lesbians compared to straight women, and gay men compared to straight men, in the following treatment conditions:

- A lesbian/straight female mechanic fixing your car engine when you leave your car at the auto repair shop;

- A gay male/straight male beautician cutting your hair at your next hair appointment.

I use occupational scenarios for a car mechanic and beautician because they represent two occupations that are seen as stereotypically "masculine" and "feminine," respectively: over $98 \%$ of car mechanics are men, while over $92 \%$ of beauticians are women (Bureau of Labor 
Statistics 2016). These conditions allow me to explore whether there is less bias against lesbians compared to straight women who work in male-dominated occupations, and whether there is less bias against gay men compared to straight men who work in female-dominated occupations.

Lastly, because nursing and elementary school teaching are both female gender-typed occupational contexts (only about $10 \%$ of nurses and $21 \%$ of elementary school teachers are male, see Bureau of Labor Statistics 2016), and they work with populations seen as particularly vulnerable or impressionable (sick people and young children), it raises the question of whether and how gay men will experience bias compared to straight men in these occupational contexts. On the one hand, based on my theory from $H 1$, it is possible that gay men will elicit more bias than straight men in these roles due to the fact that they work with vulnerable populations, which may activate negative stereotypes about gay men related to sexual predation, morality, or contagion. On the other hand, $H 2$ says that when gay men work in occupational roles that are female-typed, they will elicit less bias than straight men due to stereotypes that they are effeminate and thus possibly more apt to work in such a field. Because the two mechanisms are simultaneously present, I do not make a hypothesis here, but consider this contrast and will investigate which group is favored when this scenario occurs. To investigate this, I add the following 2 treatment conditions:

- A straight male nurse treating you when you are sick in the hospital.

- A straight male elementary school teacher teaching your young children, or young children in your community.

Including these treatment conditions helps me disentangle the effect of gender bias from sexual orientation bias against men working in elementary school teaching and nursing fields.

In sum, these 14 treatment conditions (listed out in Appendix A) allow me to make vital comparisons of estimates of bias against employees across different occupational roles, and 
across different genders and sexual orientations of the employees within these roles, to explore how different occupational contexts shape bias against gay men and lesbians in the labor force.

\section{Design Decisions}

I make several important design decisions that avoid potential pitfalls of list experiments (Torangeau and Yan 2007; Glynn 2013). First, I ask respondents how many statements make them "angry or upset" as opposed to how many they "disapprove" of in order to obtain a more conservative estimate of bias against gays and lesbians in the workforce. Anger connotes a different, stronger sentiment than simply disapproving of something, and my goal is to get a measure of how many people feel strongly negatively towards these particular occupational scenarios. Additionally, I obtain my sample from MTurk, which tends to have more young and liberal respondents compared to the general U.S. population (Coffman et al. 2017; Richey and Taylor 2012). Doing so should also produce a conservative estimate of bias against gays and lesbians in the labor market.

Next, I make efforts to avoid contrast effects. For example, if one of the non-sensitive (i.e., baseline) items was so appalling that it elicited very emotional responses from respondents, the other items would sound tame in comparison. Thus, it is important to ensure that the baseline items are comparable in their propensities to provoke anger (Kuklinski et al. 1997). As such, I selected baseline statements that are comparable in their propensity to provoke anger, as all are political in nature, and none stand out from the other in any obvious way (see Appendix A).

Furthermore, I make efforts to avoid both floor effects (when none of the items on the list anger the respondent) and ceiling effects (when all of the items on the list anger the respondent). Both situations may change the respondent's answer to one above or below their true response, as the anonymity of which specific statements upset the respondent has now disappeared. To 
address this, I selected baseline statements that are negatively correlated with each other (see Appendix A). For example, it is expected that baseline statement 1, "A violent criminal recently released from prison winning public office in your district" and baseline statement 2, "A Canadian immigrant bagging your food items at your grocery store" will offset, as statement 1 will likely anger or upset most people and statement 2 will likely anger very few people. It is also expected that baseline statement 3, "A librarian acquiring books that promote atheism for your neighborhood's public library" is likely to be negatively correlated with baseline statement 4, "A person who doesn't believe in evolution creating the course of study for the science department in your district's middle school." This design decision of negative within-list correlation is important, as it gets around the ceiling and floor effects problems, and because negative within-list correlation has been shown to reduce variance and bias (Glynn 2013). Indeed, results from a pilot study $(\mathrm{N}=203)$ that asked respondents to indicate how many items from the baseline list made them angry or upset, and then to specify which ones, suggest that I successfully avoid ceiling and floor effects with my 4 baseline statements. The modal response of baseline statements that angered respondents in the pilot study was 2; a majority indicated they were angered by statement 1 ; a minority indicated they were angered by statement 2 ; and statements 3 and 4 varied depending on the respondent, but no respondent indicated they were angered by both statements 3 and 4 .

Lastly, I chose to make the language of each condition respondent-specific, meaning that the condition directly affects the respondent in some way (i.e., a gay male/lesbian nurse treating you; a gay male/lesbian accountant doing your tax returns; a gay male/straight male beautician cutting your hair; etc.). I do so because this study seeks to obtain estimates of bias against gay men and lesbians in different occupational scenarios from consumers - meaning, those who 
would potentially receive services from and interact with the employee in question. Rather than having the respondent give their opinion about gay employees providing services to people in general, forcing respondents to imagine direct contact with them gives a more accurate estimate of their true sentiment in each scenario.

\section{Analytical Approach}

I label respondents assigned to the treatment group the "Indirect Report" group, as these participants responded to the sensitive item indirectly (i.e., within the list experiment). I label the respondents assigned to the control group the "Direct Report" group, as these participants were asked about the sensitive item directly (i.e., as a direct question). For each question $q$ and participant $i$ in the Indirect Report group, I observe $y_{q i}^{I}$, the number of the 5 statements that the respondent said "angered or upset" them. In the Direct Report method, I observe $d_{q i}$, which is equal to 1 if participant $i$ answered "yes" to the directly asked sensitive question and 0 otherwise, and $b_{q i}$, the number of the 4 baseline statements that angered the respondent. For the control group, I construct the sum of these measures, $y_{q i}^{D}=d_{q i}+b_{q i}$, which gives the number of 5 items that angered the respondent for the Direct Report group. Under truthful reporting, the expected number of items that anger or upset the respondent should be the same in the two conditions, since respondents are randomly assigned: $E\left[y_{q i}^{I}\right]=E\left[y_{q i}^{D}\right]$. However, when they differ, $E\left[y_{q i}^{I}\right]$ is a better estimate of the true population mean under the assumption that the Indirect Report method lowers the cost of telling the truth. Following analysis used by Coffman et al. (2017), I define the change in reporting as $\mu_{q} \equiv E\left[y_{q i}^{I}\right]-E\left[y_{q i}^{D}\right]$.

Also following Coffman et al. (2017), rather than simply comparing sample means, regression analysis gives a better and more precise estimate of $\mu_{q}$, as it allows me to control for 
observed demographic characteristics. ${ }^{4}$ Thus, in my results below, I report the estimated $\mu$ from the regression:

$y_{q i}=\beta X_{i}+\mu_{q} I_{i}$,

where $I_{i} \in\{0,1\}$ is an indicator variable for being in the Indirect Report group, and $y_{q i}$ is simply $y_{q i}^{I}$ or $y_{q i}^{D}$, whichever is observed for the respondent.

The vector of observed demographic controls $X_{i}$ includes age (linearly and as a quadratic), education (high school or less, some college, and bachelor's degree or more), political affiliation (Republican, Democrat, Independent), religion (Catholic, Protestant, other Christian, Jewish, no religion, other), race (white, black, Hispanic, Asian, other), gender (male, female, other/transgender), census region (Midwest, West, South, Northeast), marital status, religiosity (on a scale of 1 to 9 , where 1 is never attends church and 9 is attends church weekly), and political ideology (on a scale of 1 to 7 , where 1 is extremely conservative and 7 is extremely liberal).

\section{RESULTS}

\section{Evaluating the Design}

Before I present my results, I evaluate the design of my list experiment. To do so, I first examine a frequency table to assess if there was a low proportion of people who selected 0 and 4 in the control group, which allows me to see if I successfully avoided floor and ceiling effects. Indeed, only $7 \%$ selected 0 and only $1 \%$ selected 4 ; furthermore, the modal response to the baseline items was 2, just as it was in the pilot study. This provides further evidence that I achieved the desired negative correlation among my baseline items (Lax et al. 2016).

Next, I consider that the validity of list experiments depends on two assumptions: 1) that people are willing to tell the truth when provided increased anonymity, and 2) that there was no 
design effect (Blair and Imai 2011). For the former assumption of no liars, I do not expect that the urge to lie is so strong that respondents continue to do so even when afforded increased anonymity; the sort of bias studied here is indeed the usual target for a list experiment (Coffman et al. 2017; Lax et al. 2016; Rayburn et al. 2003). For the latter assumption of no design effect, I use the R package proposed by Blair and Imai (2012) to formally test for design effects.

A design effect is present when a respondent's answer to the baseline items changes whether or not the sensitive item (i.e., the treatment statement) is present (Blair and Imai 2012; Imai 2011). In other words, the presence of the treatment condition should not affect the respondent's answers to the control items. Following Blair and Imai (2012), I use the List package in $\mathrm{R}$ to implement a likelihood ratio test on each of my 14 treatment groups that tests whether the observed pattern was due to a design effect. If the p-value on this test is more than .05 , I will not be able to reject the null hypothesis of no design effect, and can move forward in my analysis under the assumption of no design effect. Indeed, the p-values on each of the 14 tests are higher than .05 (see Appendix B), so I move forward under the assumption of no design effect.

\section{Descriptive Statistics}

Descriptive statistics of my sample $(\mathrm{N}=6,233)$ are shown in Table 1 . My sample is diverse, with a broad range of demographic characteristics, but it is not a representative sample of the U.S. Approximately $53 \%$ are female; the mean age is 35 ; about $53 \%$ have at least a Bachelor's degree, and less than $21 \%$ identify as Republican. As expected, MTurk yielded a sample that is younger, more educated, and more liberal than the U.S. general population. Assessment of Social Desirability 
In Table 2, I assess the presence of social desirability bias in responses. Following Coffman et al. (2017), Column 1 shows the percent reporting the sensitive answer in the Direct Report method. Column 2 shows the change in reporting, $\mu$, as a percent of the total sample, estimated using a regression with controls, as described above. Column 3 estimates the percent, in this sample, who are angered by the sensitive item, and is derived by adding Columns 1 and 2 . Column 4 gives the percent increase in reporting anger towards the sensitive item under the Indirect Report method; it is derived by dividing Column 2 by Column 1. I present heteroscedasticity-robust standard errors for the treatment effect $\mu$ in Table 2 . When calculating the estimated true fraction answering "yes" to the sensitive item (Column 3), I use the bootstrap to calculate standard errors (estimated from 1,000 repetitions, stratified on treatment).

Table 2 shows that the Indirect Report method significantly increases reports of bias compared to the Direct Report method on three conditions: A gay male nurse treating you when you are sick in the hospital; A gay male elementary school teacher teaching your young children, or young children in your community; and A lesbian elementary school teacher doing the same. In the Direct Report method, about $6 \%$ of respondents report that they are angered by the idea of a gay male nurse treating them while sick in the hospital; in the Indirect Report method, this increases to $16 \%$. The 9.6 percentage point difference is significant at $p<.10$ (two-tailed test) and represents a $157 \%$ increase in the fraction of the sample reporting being angered by the idea of a gay male nurse treating them when they are sick when asked indirectly as opposed to directly.

The percentage of respondents who say that they would be angered by a gay male elementary school teacher teaching their young children is $10 \%$ when asked directly, but it is $25 \%$ when asked indirectly. Similarly, the percentage reporting that they would be angered by a lesbian elementary school teacher teaching their young children is $10 \%$ when asked directly, but 
it is $24 \%$ when asked indirectly. The 14 and 15 percentage-point differences in these two conditions are both significant at $p<.01$, representing a $152 \%$ increase in the fraction of the sample reporting anger against a gay male elementary school teacher and against a lesbian elementary school teacher when asked indirectly as opposed to directly. ${ }^{5}$

\section{Assessment of Hypotheses}

As discussed above, estimates in Column 3 of Table 2 are thought to be free of, or less influenced by, social desirability bias, as this is the estimate of anger when respondents were asked indirectly. Thus Column 3 represent the estimated true fraction of the sample that has anger towards each of the treatment conditions (Coffman et al. 2017; Blair and Imai 2011). As such, I assess each of my hypotheses using estimates from Column 3.

Findings provide strong evidence for Hypothesis 1, that gay men and lesbians serving in occupational contexts where they work closely with young children or adolescents will elicit more bias compared to those who do not work closely with such populations. The estimated percent of the sample who are angered by gay and lesbian elementary school teachers $(25 \%$ and $24 \%$, respectively) and by gay and lesbian high school basketball coaches (19\% and $15 \%$, respectively) are all much higher than the estimated percent angered by gay and lesbian accountants (-1\%, which can be thought of as essentially $0 \%$, and $3 \%$, respectively) ${ }^{6}$ As predicted, gay men and lesbians who work closely with children or youth elicit much more bias than those who do not work with such populations.

Next, I assess Hypothesis 2, that gay individuals, especially gay men, who serve in occupational contexts where they are required to work closely with those who are ill in a hospital will elicit more bias compared to gay individuals who do not work in such occupational contexts. Results provide evidence that this is true for gay men, but not lesbians. The estimated 
percent of the sample angered by a gay male nurse treating them while sick in the hospital was $16 \%$, while only $0.1 \%$ of respondents report anger against a lesbian nurse doing the same.

For a visual representation of the differences in bias against gay men and lesbians who work with populations seen as particularly vulnerable or impressionable (sick people and youth) compared to those who do not work with such populations (accountants), see Figure 2.

Significant differences across contexts can be assessed by examining the standard errors in Column 3 of Table 2, and more clearly by examining the error bars in the estimates shown in Figure 2; when the bars do not overlap, the difference between estimates are significant. Along these lines, when the bars overlap with 0 , they can be thought of as no anger against this condition, as the estimate is not significantly different from 0.

Next, I assess Hypothesis 3, that gay men and lesbians working in occupations stereotypically seen as appropriate for the other sex will elicit less bias compared to straight men and women working in these same occupations. Column 3 of Table 2 shows that $7 \%$ of the sample are angered by a straight female car mechanic fixing their car engine, while 5\% are angered by a lesbian doing the same. In other words, respondents expressed slightly less anger towards a lesbian in this masculine-gendered role compared to a straight woman. Similarly, about $-1 \%$ (which can be thought of as essentially $0 \%$ ) of the sample are angered by a gay male beautician cutting their hair, while about $2 \%$ are angered by a straight male beautician doing the same. Thus, respondents expressed slightly less anger (in fact, no anger) towards a gay male in this feminine-gendered role, while anger towards a straight male serving in this role was very marginal. This hints that Hypothesis 3 has some merit, as estimates are moving in the direction predicted. However, estimates are not significantly different from each other, nor are they significantly different from 0 , as error bars for all estimates overlap with each other and with 0 
(graph not shown). So, there is not compelling evidence to support Hypothesis 3, compared to the very clear evidence for Hypothesis 1 and 2.

Lastly, I assess bias against gay men (compared to straight men) in occupational scenarios where the two mechanisms simultaneously occur: the occupation is female gendertyped, and the occupation works with populations seen as particularly vulnerable (sick people, youth). I do so by comparing estimates of anger against gay men and straight men in the roles of nursing and elementary school teaching. Column 3 shows that only about $1 \%$ of the sample were angered by a straight male nurse while $16 \%$ were angered by a gay male nurse. It also shows that only $4 \%$ of the sample were angered by a straight male elementary school teacher while $25 \%$ were angered by a gay male elementary school teacher (both significant differences). Subtracting the estimates of anger against straight males from gay males gives an estimate of about $15 \%$ angered about a gay male nurse solely because the man in the role is gay, and an estimate of about $21 \%$ angered by a gay male elementary school teacher, again, solely because the man in the role is gay. In both cases, the effect of gay identity is much stronger than male identity when estimating consumer bias against men in these occupational contexts.

\section{DISCUSSION AND IMPLICATIONS}

This study examines how and whether bias against gay men and lesbians in the labor force varies across specific occupational scenarios, where different stereotypes about gay individuals may be evoked. Using a list experiment, I obtain estimates of bias against gay men and lesbians in certain occupational contexts while eliminating or reducing social desirability bias. Results provide evidence that bias against gay men and lesbians is not uniform across all occupations or subgroups of gay employees. 
Results show that gay men and lesbians who serve in occupations that work closely with populations thought to be particularly impressionable or vulnerable (i.e., elementary school teachers, nurses, high school coaches) elicit more bias than gay men and lesbians who do not work in such a field (i.e., accountants). Occupational contexts where gay employees are in charge of particularly vulnerable populations may evoke respondents' negative stereotypes about gay individuals, such as that they are sexual predators, are negative influences on children, and/or have HIV/AIDS. If this was the case, we'd expect bias to increase in scenarios where such stereotypes are likely to be evoked (such as the idea of a gay person teaching elementary school students, coaching high school athletes after school, or caring for sick patients in the hospital) compared to occupational scenarios where these stereotypes are not likely to be evoked (such as the idea of a gay person serving as an accountant). Indeed, results confirm this pattern.

The exception to this was the lesbian nurse condition, which elicited almost no anger from respondents. This may be because stereotypes around gay people as predatory or as having HIV/AIDS are often associated with gay men more than lesbians (Badgett 1995; Knauer 2000; Herek 2009). However, the occupational roles eliciting the highest estimates of bias for lesbians were elementary school teachers and high school coaches - and these estimates were comparable to those for gay men in these roles. This suggests that lesbians are not free from bias in roles where they work closely with youth.

While some researchers argue that compared to the early 1990s, gay men and lesbians have become less culturally and politically resonant in regards to "stranger danger" narratives (Stone 2018), the large proportion angered by gay male nurses, gay and lesbian elementary school teachers and high school basketball coaches suggests that large percentages of consumers still hold such narratives today. In fact, estimates from this study can be considered conservative 
estimates due to the younger, more educated, and more liberal sample of respondents responding to the survey. Such biases against gay and lesbians employees can have long-term implications on their health and economic outcomes, as studies show that prejudice against sexual minorities has been linked to reduced life satisfaction, increased internalized homophobia, and negative psychological, health, and job-related consequences (Meyer 2003).

Next, this research assessed whether the idea of gay men and lesbians serving in occupational roles seen as more appropriate for the other sex could result in an advantage for gays and lesbians compared to their straight counterparts in such roles, precisely due to the stereotype that they are gender non-conforming. Results reveal that respondents were slightly more angered by a straight male beautician cutting their hair compared to a gay male beautician doing the same, and slightly more angered by a straight female mechanic fixing their car engine compared to a lesbian mechanic doing the same, but differences are small and insignificant. Further exploration is needed to assess whether certain occupational contexts, and specific stereotypes about gay men and lesbians, can ever result in "positive consequences" (Pedulla 2014) for gay and lesbian employees. While my study did not find evidence of advantages for gay men and lesbians in these roles, I also do not find evidence of bias against them in these scenarios.

Generally speaking, this study helps illustrate how occupational context, and stereotypes about gay individuals evoked through these contexts, can play a role in bias against gay and lesbian employees. Results suggest that bias cannot be reduced to a general animosity towards gay individuals; rather, results suggest that these contextual differences in anti-gay bias result from the fact that anti-gay bias is often based, at least in part, on stereotypes related to both sexuality and gender. Different occupational scenarios have the power to activate different 
stereotypes about gay men and lesbians, which in turn, can influence respondents' opinions about which occupations are appropriate for gay men and lesbians and which are not.

One might ask whether alternative explanations for results from this study are plausible. For example, the rate at which lesbians and gay men are actually employed within certain occupations may play a role in bias, as actual rates of gay men and lesbians employed in each occupation may differ, and this could influence respondents' comfort with non-straight workers in these jobs. Indeed, a study that assesses the rates at which gay men and lesbians are employed in certain occupations compared to straight individuals finds that gay men are overrepresented as accountants while lesbians are underrepresented $(+20 \%$ and $-34 \%$, respectively); that gay men are overrepresented as elementary school teachers while lesbians are underrepresented $(+56 \%$ and $-48 \%$, respectively); and that gay men are overrepresented as nurses while lesbians are underrepresented ( $+446 \%$ and $-40 \%$, respectively) (Baumle et al. 2009). However, interestingly, the results of bias obtained from this study do not correlate with occupational sorting based on sexual orientation mentioned above. For instance, I find high estimates of bias against gay male nurses and elementary school teachers - two occupations where gay men are overrepresented, as well as high estimates of bias against lesbian elementary school teachers - though there, lesbians are underrepresented (Baumle et al. 2009). This suggests that bias is not necessarily driven by notions of familiarity from respondents. In fact, other research on wage discrimination based on sexual orientation finds that occupational sorting explains little or no variation in the wage differences between gay and heterosexual individuals (Antecol et al. 2008).

Another alternative explanation could have to do with the differences in the status or pay of the occupational scenarios, in that perhaps consumers have less bias towards gay men and lesbians employed in higher-status and higher-paying positions compared to those considered 
lower-status. Indeed, Webster et al. (1998) find less penalties for gay men with a high-status occupation compared to those with a low-status occupation (by comparing a gay dishwasher to a gay computer systems analyst). Thus, it can be argued that the differences in bias stems from the status advantage of being an accountant compared to an elementary school teacher, high school coach, or nurse. However, this does not explain the lack of bias towards gay male beauticiansan occupation that is not particularly high-status.

Thus, the large variation in bias that this study finds suggests that bias against gay men and lesbians in the labor market cannot be attributed to: a general distaste for gay employees; a general belief that gay individuals are less competent than straight individuals; occupational sorting and respondent familiarity of such sorting; or status-based differences in occupations. Variation in levels of bias against gay men and lesbians in the labor force must then be attributed, at least in part, to something else. I argue that it is occupational context, and stereotypes about gay people likely evoked within certain contexts, that respondents are reacting to when assessing their sentiment towards gay employees in various occupational scenarios. 


\section{REFERENCES}

Antecol, H., Jong, A., \& Steinberger, M. (2008). The sexual orientation wage gap: The role of occupational sorting and human capital. Industrial \& Labor Relations Review 4: 518-43.

Badgett, MVL. (1995). The Wage Effects of Sexual Orientation Discrimination. ILR Review 48(4): $726-39$.

Banaji, M. (2002). The Social Psychology of Stereotypes. Pp. 15100-104 in International Encyclopedia of the Social and Behavioral Sciences, edited by Neil Smelser and Paul Baltes. New York: Pergamon.

Baumle, A.K., \& Poston, D. (2011). The economic cost of being homosexual: A multilevel analysis. Social Forces 89: 1005-1031.

Baumle, Amanda. K., D’Lane Compton, and Dudley L. Poston. 2009 Same-sex Partners: The Demography of Sexual Orientation. Albany, NY: SUNY Press.

Blair, G. and Imai, K. (2012). Statistical Analysis of List Experiments. Political Analysis 20:47-77.

Blandford, J.M. (2003). The Nexus of Sexual Orientation and Gender in the Determination of Earnings. Industrial \& Labor Relations Review 56(4): 622-42.

Bureau of Labor Statistics. (2016). Table 11 Employed Persons by Detailed Occupation, Sex, Race, and Hispanic or Latino Ethnicity, 2014, Current Population Survey. Retrieved August 2017 (http://www.bls.gov/cps/cpsaat11.pdf).

Coffman, K.B., Coffman, L. and Ericson, K. (2017). The Size of the LGBT Population and the Magnitude of Anti-Gay Sentiment are Substantially Underestimated. Management Science 63(10): 3168-3186.

Colgan, Fiona, Chris Creegan, Aidan McKearney, and Tessa Wright. 2008. "Lesbian Workers: Personal Strategies Amid Changing Organisational Responses to 'Sexual Minorities' in UK Workplaces." Journal of Lesbian Studies 12(1):31-45.

Compton, C.A. and Dougherty, D. (2017). Organizing Sexuality: Silencing and the Push-Pull Process of Co-Sexuality in the Workplace. Journal of Communication 67(6): 874-896.

Connell, Catherine. 2015. School's out: Gay and Lesbian Teachers in the Classroom. Oakland, California: University of California Press.

Coutts, E. and Jann, B. (2011). Sensitive Questions in Online Surveys: Experimental Results for the Randomized Response Technique (RRT) and the Unmatched Count Technique (UCT). Sociological Methods and Research 40(1): 169-193.

Cowan, S., Wu, L., Makela, S., and England, P. (2016). Alternative estimates of lifetime prevalence of abortion from indirect survey questioning methods. Perspectives on Sexual and Reproductive Health 48(4): 229-234.

Denissen, A.M. and Saguy, A. (2014). Gendered Homophobia and the Contradictions of Workplace Discrimination for Women in the Building Trades. Gender and Society 28(3):381-403.

Elmslie, B. and Tebaldi, E. (2007). Sexual Orientation and Labor Market Discrimination. Journal of Labor Research 28:436-53.

Family Research Council. (2002). "Homosexuality and Child Sexual Abuse." Retrieved March 2017. (https://www.frc.org/get.cfm?i=is02e3).

Family Research Institute. (2006). "Getting the facts: Same-sex marriage.” Retrieved May 2017 (http://familyresearchinst.org/).

Fejes, F. (2008). Gay Rights and Moral Panic: The Origins of America's Debate on Homosexuality. New York: Palgrave Macmillan. 
Fiske, S.T. (1998). Stereotyping, Prejudice and Discrimination. Pp. 357-411 in The Handbook of Social Psychology, edited by Daniel T. Gilbert, Susan T. Fiske, and Gardner Lindzey. Boston: McGraw-Hill.

Flake, D. (2017). Employer Liability for Non-Employee Discrimination. 58 B.C.L. Rev. 1169, https://lawdigitalcommons.bc.edu/bclr/vol58/iss4/4.

Ford, J. and England, P. (2016). Who Thinks Sex with Same-Sex Partners is 'Wrong.' Blog post, Contexts. (https://contexts.org/blog/who-thinks-sex-with-same-sex-partners-is-wrong/).

Freund, K., Watson, R., \& Rienzo, D. (1989). Heterosexuality, homosexuality, and erotic age preference. The Journal of Sex Research, 26 (1), 107-117.

Giuffre, Patti, Kirsten Dellinger, and Christine L. Williams. 2008. "No Retribution for Being Gay? Inequality in Gay-Friendly Workplaces.” Sociological Spectrum 28(3):254-77.

Groth, A.N., \& Birnbaum, H.J. (1978). Adult sexual orientation and attraction to underage persons. Archives of Sexual Behavior 7 (3), 175-181.

Heerwig, J. and McCabe, B. (2009). Education and Social Desirability Bias: The Case of a Black Presidential Candidate. Social Science Quarterly 90(3): 674-686.

Herek, G. (1991). Stigma, prejudice, and violence against lesbians and gay men. In J. C. Gonsiorek \& J. D. Weinrich (Eds.), Homosexuality: Research implications for public policy (pp. 60-80). Thousand Oaks, CA, US: Sage Publications, Inc.

Herek, G. (2002). Heterosexuals' attitudes toward bisexual men and women in the United States. Journal of Sex Research 39, 264-274.

Herek, G. (2009). Sexual Stigma and Sexual Bias in the US: A Conceptual Framework. Contemporary Perspectives on Lesbian, Gay, and Bisexual Identities 54, 183-195.

Horton, J.J., Rand, D. and Zeckhauser, R. (2011). The Online Libratory: Conducting Experiments in a Real Labor Market. Experimental Economics 14(3): 399-425.

Hunt, M.O., Wise, L. Jipguep, M.C., Cozier, Y. and Rosenberg, L. (2007.) "Neighborhood Racial Composition and Perceptions of Racial Discrimination: Evidence from the Black Women's Health Study." Social Psychology Quarterly 70(3):272-89.

Imai, K. (2011). Multivariate Regression Analysis for the Item Count Technique. Journal of the American Statistical Association 106(494): 407-416.

Janus, A.L. (2010). The Influence of Social Desirability Pressures on Expressed Immigration Attitudes. Social Science Quarterly 91(4): 928-946.

Jenny, C., Roesler, T. A., \& Poyer, K. L. (1994). Are children at risk for sexual abuse by homosexuals? Pediatrics, 94(1), 41-44.

Johnson, C. (1995.) Sexual Orientation as a Diffuse Status Characteristic: Implications for Small Group Interaction. Advances in Group Processes 12: 115-137.

Kaiser Family Foundation. (2006). "Survey of Americans on HIV/AIDS." (https://www.kff.org/global-health-policy/poll-finding/survey-of-americans-on-hivaids/).

Kayal, P.M. (1993). Bearing Witness: Gay Men's Health Crisis and the Politics of AIDS. Boulder: Westview Press.

Kitzinger, C. and Peel, E. (2005). The De-Gaying and Re-Gaying of AIDS: Contested Homophobias in Lesbian and Gay Awareness Training. Discourse \& Society 16(2):173-97.

Knauer, N.J. (2000). Homosexuality as Contagion: From the Well of Loneliness to the Boy Scouts. Hofstra Law Review 29(2) Article 2. (http://scholarlycommons.law.hofstra.edu/hlr/vol29/iss2/2).

Kuklinski, J.H., Cobb, M., and Gilens, M. (1997.) Racial Attitudes and the 'New South.' Journal of Politics 59(2): 323-349. 
LaBrie, J.W. and Earleywine, M. (2000). Sexual Risk Behaviors and Alcohol: Higher Base Rates Revealed Using the Unmatched-Count Technique. Journal of Sex Research 37(4): 321-326.

Lax, J.R., Phillips, J. and Stollwerk, A. (2016). Are Survey Respondents Lying about their Support for Same-Sex Marriage? Lessons from a List Experiment. Public Opinion Quarterly 80 (2): 510533.

Lewis, G. and Gossett, C. (2018). Changing Public Opinion on Same-Sex Marriage: The Case of California. Politics and Policy 36(1): 4-30.

Meyer, Ilan. H. (2003). "Bias, Social Stress, and Mental Health in Lesbian, Gay, and Bisexual Populations: Conceptual Issues and Research Evidence." Psychological Bulletin 129(5), 674697.

Mishel, E. (2016). Discrimination against Queer Women in the U.S. Workforce: A Résumé Audit Study. Socius: Sociological Research for a Dynamic World 2:1-17.

Mize, T. (2016). Sexual Orientation in the Labor Market. American Sociological Review 81(6): 11321160 .

Mize, T. and Manago, B. (2018). The Stereotype Content of Sexual Orientation. Social Currents 1-21.

Movement Advancement Project. (2019). "Non-Discrimination Laws." https://www.lgbtmap.org/equality-maps/non discrimination laws.

Orzechowicz, David. 2016. "The Walk-In Closet: Between 'Gay-Friendly' and 'Post-Closeted' Work.” Pp. 187-213 in Research in the Sociology of Work. Vol. 29, edited by S. Vallas. Emerald Group Publishing Limited.

Paolacci, G., Chandler, J. and Ipeirotis, P. (2010.) Running Experiments on Amazon Mechanical Turk. Judgment and Decision Making 5(5): 411-419.

Pedulla, D. (2014). The Positive Consequences of Negative Stereotypes: Race, Sexual Orientation, and the Job Application Process. Social Psychology Quarterly 77(1): 75-94.

Rayburn, N., Earley, M. and Davidson, G. (2003.) An Investigation of Base Rates of Anti-Gay Hate Crimes Using the Unmatched-Count Technique. Journal of Aggression, Maltreatment and Trauma 6(2): 137-150.

Rand, D.G. (2012). The Promise of Mechanical Turk: How Online Labor Markets Can Help Theorists Run Behavioral Experiments. Journal of Theoretical Biology 299: 172-179.

Ridgeway, C.L. and Correll, S. (2004). Unpacking the Gender System: A Theoretical Perspective on Gender Beliefs and Social Relations. Gender \& Society 18(4):510-31.

Ridgeway, C.L. (2009). Framed Before We Know It: How Gender Shapes Social Relations. Gender and Society 23:145-60.

Richey, S. and Taylor, B. (2012). "How Representative are Amazon Turk Workers?" The Monkey Cage. Retrieved May 2016 (http://themonkeycage.org/2012/12/how-representative-are-amazonmechanical-turk-workers).

Rumens, Nick and Deborah Kerfoot. 2009. "Gay Men at Work: (Re)Constructing the Self as Professional." Human Relations 62(5):763-86.

Singh, S., Mitsch, A. \& Wu, B. (2017). HIV Care Outcomes Among Men Who Have Sex With Men With Diagnosed HIV Infection — United States, 2015. MMWR Morb Mortal Wkly 66:969-974.

Sniderman, P.M. and Carmines, E.G. (1997.) Reaching Beyond Race. Harvard University Press.

Stone, A.L. (2018.) Frame Variation in Child Protectionist Claims: Constructions of Gay Men and Transgender Women as Strangers. Social Forces: 1-22.

Tilcsik, A. (2011.) Pride and Bias: Employment Discrimination against Openly Gay Men in the United States. American Journal of Sociology 117(2), 586-626. 
Tourangeau, R. and Yan, T. (2007). Sensitive Questions in Surveys. Psychological Bulletin 133(5): 859.

Wang, Lu-in. (2016). When the Customer Is King: Employment Discrimination as Customer Service. Virginia Journal of Social Policy and the Law 23: U. of Pittsburgh Legal Studies Research Paper No. 2016-01.

Webster, M., Hysom, S.J., and Fullmer, S. (1998). Sexual Orientation and Occupation as Status. Advances in Group Processes 15: 1-21.

Weinberg, G. (1972). Society and the healthy homosexual. Garden City, New York Anchor Press Doubleday \& Co.

Williams, Christine L. (1992). "The Glass Escalator: Hidden Advantages for Men in the 'Female' Professions." Social Problems 39(3):253-267.

Williams, Christine and Patti Giuffre. (2011). "From Organizational Sexuality to Queer Organizations: Research on Homosexuality and the Workplace: Homosexuality and the Workplace." Sociology Compass 5(7):551-63.

Williams, Christine. L., Giuffre, P. A., \& Dellinger, K. (2009). The gay-friendly closet. Sexuality Research and Social Policy 6: 29-45.

Wright, Tessa. 2011. "A 'Lesbian Advantage'?: Analysing the Intersections of Gender, Sexuality and Class in Male-dominated Work" edited by F. Colgan. Equality, Diversity and Inclusion: An International Journal 30(8):686-701.

\footnotetext{
${ }^{1}$ Respondents were paid $\$ 0.35$ to take the survey, which is within the estimate of recommended pay per minute of work for MTurk workers. Recruitment occurred by listing the survey on MTurk, and by workers clicking on the link for the advertised assignment. Upon clicking the link, they were asked if they were over 18 and reside in the U.S., two requirements for taking the survey.

${ }^{2}$ I did not include statements about bisexual or transgender employees due to limitations in the number of treatment statements I could reasonably include in the experiment, and due to specific stereotypes about gay men and lesbians that my list experiment attempts to directly assess. Stereotypes about bisexual and transgender individuals may differ from those discussed in the paper. Future research can employ similar techniques to assess how stereotypes specific to bisexuals or transgender individuals affect their labor market experiences, and how bias may vary by occupational context for these groups as well.

${ }^{3}$ This hypothesis assumes that any amount of bias because the person is gay/lesbian, irrespective of occupational context, is cancelled out by the benefit of being seen as more feminine/masculine compared to the straight person, and thus as more appropriate for the occupation in question.

${ }^{4}$ For additional discussions of the limitations of only using mean sample comparisons to analyze list experiments, see Blair and Imai (2011). Of course, except for random error, randomization ensures that demographic controls should be uncorrelated with whether the respondent received the treatment or not, and thus results should be affected little by the regression-based adjustment.

${ }^{5}$ There were no significant differences between estimates from the Indirect Report method and the Direct Report method on any conditions besides a gay male nurse, and a gay and lesbian elementary school teacher. However, non-significant negative values on some conditions suggest that there are some cases where the Indirect Report method seems to work in the opposite way than one would expect. For example, the percentage change in the lesbian nurse condition between the Direct Report method and the Indirect Report method is -98\% (Table 2, Column 4), which implies that respondents are less likely to report anger against a lesbian nurse when asked indirectly, than when asked directly. The direction of this result suggests that respondents want to appear to be angered about a lesbian nurse caring for them when they are sick, but are in fact comfortable with a lesbian nurse doing so. Indeed, other list experiments/UCTs measuring bias find that social desirability sometimes works in the opposite way. For example, Rayburn et al. (2003), find that verbal threats toward a gay person were more frequently endorsed in a direct question method compared to a veiled (UCT) method. They suggest that students might exaggerate their involvement in this behavior when answering directly, because they may perceive it as socially desirable to give the impression that one is a "tough guy" when confronted with gay people. As another example,
} 
Lax et al. (2016) find that well-educated Republicans are more likely to report on a list experiment that they support marriage equality compared to a direct question approach. In this sense, social desirability may not necessarily be unidirectional. Yet the non-significance of these negative results also means they may simply be reflective of noise in the data.

${ }^{6}$ The estimated percent can be slightly negative because of the regression adjustment for covariates. 


\section{Figures}

Figure 1: List Experiment Design

\begin{tabular}{l}
\multicolumn{1}{|c|}{ Treatment Group } \\
How many statements anger/ \\
upset you? \\
- Baseline statement 1 \\
- Baseline statement 2 \\
- Baseline statement 3 \\
- Baseline statement 4 \\
- Sensitive Statement \\
Answer: 0-5
\end{tabular}

\section{Control Group}

How many statements anger/ upset you?

- Baseline statement 1

- Baseline statement 2

- Baseline statement 3

- Baseline statement 4

Answer: 0-4

Does the following statement anger/upset you? Sensitive Statement

Answer: Yes/No 
Figure 2: Estimated Percent Angered

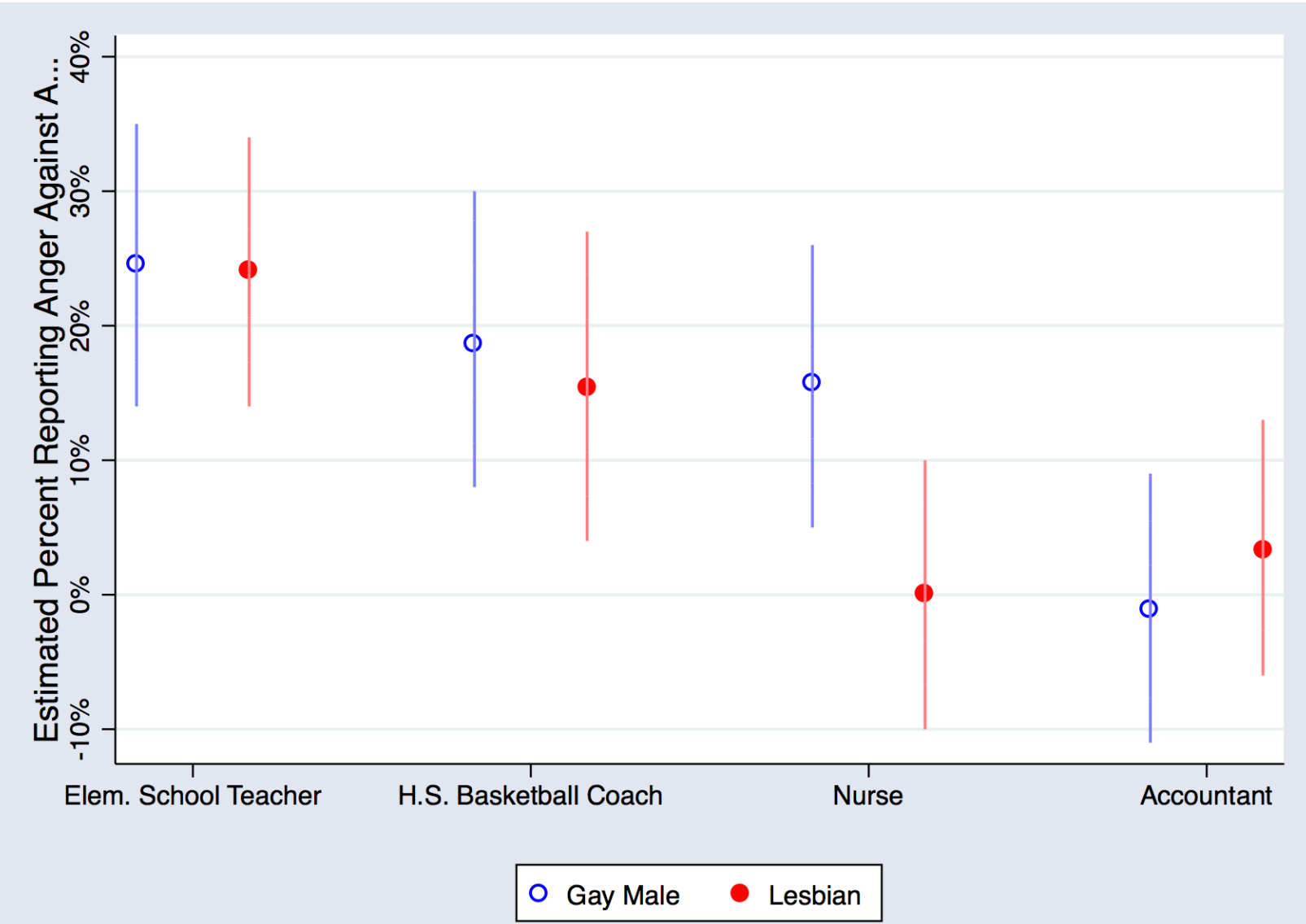

Note: Predicted probabilities correspond to regression results in Table 2, Column 3. Bars indicate confidence intervals at the $95 \%$ level. 


\section{Tables}

Table 1: Descriptive Statistics $(\mathrm{N}=6, \mathbf{2 3 3})$

\begin{tabular}{|c|c|c|c|c|c|}
\hline Variable & Mean & Std. Dev. & Variable & Mean & Std. Dev. \\
\hline \multicolumn{3}{|l|}{ Gender } & \multicolumn{3}{|l|}{ Parental Status } \\
\hline Male & 0.47 & 0.50 & Has Children & 0.41 & 0.49 \\
\hline Female & 0.53 & 0.50 & Has Children under 18 & 0.33 & 0.47 \\
\hline Other & 0.00 & 0.07 & \multicolumn{3}{|l|}{ Political Party Affiliation } \\
\hline Mean age & 34.78 & 11.33 & Republican & 0.21 & 0.40 \\
\hline \multicolumn{3}{|l|}{ Age Categories } & Democrat & 0.40 & 0.49 \\
\hline 30 or younger & 0.44 & 0.50 & Independent/Other & 0.39 & 0.49 \\
\hline $31-50$ & 0.45 & 0.50 & \multicolumn{3}{|c|}{ Religiosity (church attendance) } \\
\hline 51 or older & 0.12 & 0.32 & Never & 0.45 & 0.50 \\
\hline \multicolumn{3}{|l|}{ Race } & $<$ Once a year & 0.16 & 0.37 \\
\hline White & 0.75 & 0.43 & Once a year & 0.07 & 0.25 \\
\hline Black & 0.09 & 0.28 & Several times/year & 0.12 & 0.33 \\
\hline Hispanic & 0.05 & 0.22 & Once a month & 0.03 & 0.17 \\
\hline Asian & 0.07 & 0.26 & 2-3 times/month & 0.04 & 0.21 \\
\hline Other or Mixed & 0.04 & 0.20 & Nearly every week & 0.04 & 0.20 \\
\hline Immigrant & 0.06 & 0.23 & Every week & 0.07 & 0.25 \\
\hline Heterosexual & 0.88 & 0.32 & $>$ Once a week & 0.02 & 0.15 \\
\hline \multicolumn{3}{|l|}{ Education } & \multicolumn{3}{|l|}{ Religion } \\
\hline High school & 0.10 & 0.29 & Protestant & 0.15 & 0.36 \\
\hline Some College & 0.37 & 0.48 & Catholic & 0.15 & 0.36 \\
\hline Bachelor's & 0.38 & 0.49 & Jewish & 0.02 & 0.15 \\
\hline $\mathrm{MA}+$ & 0.15 & 0.36 & Christian & 0.21 & 0.41 \\
\hline \multicolumn{3}{|l|}{ Region } & Other & 0.10 & 0.30 \\
\hline West & 0.21 & 0.41 & No religion & 0.37 & 0.48 \\
\hline Midwest & 0.21 & 0.41 & \multicolumn{3}{|l|}{ Political Ideology } \\
\hline South & 0.39 & 0.49 & Extremely liberal & 0.12 & 0.32 \\
\hline Northeast & 0.20 & 0.40 & Liberal & 0.26 & 0.44 \\
\hline \multicolumn{3}{|c|}{ Yearly personal income } & Slightly liberal & 0.14 & 0.35 \\
\hline$<\$ 20 \mathrm{k}$ & 0.30 & 0.46 & Moderate & 0.23 & 0.42 \\
\hline$\$ 20 \mathrm{k}-\$ 39 \mathrm{k}$ & 0.27 & 0.45 & Slightly conserv. & 0.11 & 0.31 \\
\hline$\$ 40 \mathrm{k}-\$ 69 \mathrm{k}$ & 0.27 & 0.45 & Conservative & 0.11 & 0.31 \\
\hline$\$ 70 \mathrm{k}+$ & 0.15 & 0.36 & Extremely conserv. & 0.03 & 0.18 \\
\hline Married & 0.40 & 0.49 & Knows someone LGBT & 0.78 & 0.42 \\
\hline
\end{tabular}




\section{Table 2: Effect of Indirect Report on Sensitive Item}

\begin{tabular}{|c|c|c|c|c|c|c|}
\hline Item & $\begin{array}{c}\text { Column 1: } \\
\text { Percent } \\
\text { Reporting } \\
\text { Sensitive } \\
\text { Answer, Direct } \\
\text { Report }\end{array}$ & $\begin{array}{c}\text { Column 2: } \\
\text { Change in } \\
\text { Reporting of } \\
\text { Sensitive } \\
\text { Answer, } \\
\text { Indirect Report }\end{array}$ & $\begin{array}{c}\text { Column 3: } \\
\text { Estimated } \\
\text { True } \\
\text { Fraction for } \\
\text { Sensitive } \\
\text { Answer }\end{array}$ & $\begin{array}{r}\text { Column } 4 \\
\text { Percentage } \\
\text { Change in } \\
\text { Sensitive } \\
\text { Answer, } \\
\text { Indirect Rep }\end{array}$ & $\begin{array}{l}: \\
\text { e } \\
\text { a }\end{array}$ & Obs \\
\hline Gay Male Nurse & $\begin{array}{c}6.14 \\
{[1.45]}\end{array}$ & $\begin{array}{c}9.62 \\
{[5.18]}\end{array}$ & $\begin{array}{l}15.76 \\
{[5.39]}\end{array}$ & $156.68 \%$ & $*$ & 2169 \\
\hline Lesbian Nurse & $\begin{array}{c}3.61 \\
{[1.12]}\end{array}$ & $\begin{array}{c}-3.53 \\
{[4.76]}\end{array}$ & $\begin{array}{c}0.08 \\
{[5.07]}\end{array}$ & $-97.78 \%$ & & 2171 \\
\hline Straight Male Nurse & $\begin{array}{c}1.71 \\
{[0.60]}\end{array}$ & $\begin{array}{c}-0.27 \\
{[4.85]}\end{array}$ & $\begin{array}{c}1.44 \\
{[5.13]}\end{array}$ & $-15.79 \%$ & & 2175 \\
\hline Gay Male Elem School Teacher & $\begin{array}{c}9.75 \\
{[1.79]}\end{array}$ & $\begin{array}{l}14.80 \\
{[5.52]}\end{array}$ & $\begin{array}{l}24.55 \\
{[5.55]}\end{array}$ & $151.79 \%$ & $* * *$ & 2170 \\
\hline Lesbian Elem School Teacher & $\begin{array}{c}9.57 \\
{[1.76]}\end{array}$ & $\begin{array}{c}14.5 \\
{[5.34]}\end{array}$ & $\begin{array}{l}24.07 \\
{[5.32]}\end{array}$ & $151.52 \%$ & $* * *$ & 2172 \\
\hline Straight Male Elem. Sch. Teacher & $\begin{array}{c}1.52 \\
{[0.57]}\end{array}$ & $\begin{array}{c}2.52 \\
{[4.99]}\end{array}$ & $\begin{array}{c}4.04 \\
{[5.17]}\end{array}$ & $165.79 \%$ & & 2171 \\
\hline Gay Male H.S. Basketball Coach & $\begin{array}{l}14.78 \\
{[1.84]}\end{array}$ & $\begin{array}{c}3.88 \\
{[5.44]}\end{array}$ & $\begin{array}{l}18.66 \\
{[5.60]}\end{array}$ & $26.25 \%$ & & 2172 \\
\hline Lesbian H.S. Basketball Coach & $\begin{array}{l}10.81 \\
{[1.62]}\end{array}$ & $\begin{array}{c}4.62 \\
{[5.62]}\end{array}$ & $\begin{array}{l}15.43 \\
{[5.73]}\end{array}$ & $42.74 \%$ & & 2174 \\
\hline Lesbian Mechanic & $\begin{array}{c}1.43 \\
{[0.71]}\end{array}$ & $\begin{array}{c}3.54 \\
{[4.87]}\end{array}$ & $\begin{array}{c}4.97 \\
{[4.96]}\end{array}$ & $247.55 \%$ & & 2171 \\
\hline Straight Female Mechanic & $\begin{array}{c}1.93 \\
{[0.64]}\end{array}$ & $\begin{array}{c}4.6 \\
{[4.94]}\end{array}$ & $\begin{array}{c}6.53 \\
{[4.84]}\end{array}$ & $238.34 \%$ & & 2170 \\
\hline Gay Male Beautician & $\begin{array}{c}3.93 \\
{[1.16]}\end{array}$ & $\begin{array}{c}-5.21 \\
{[4.70]}\end{array}$ & $\begin{array}{c}-1.28 \\
{[4.83]}\end{array}$ & $-132.57 \%$ & & 2170 \\
\hline Straight Male Beautician & $\begin{array}{c}2.58 \\
{[0.74]}\end{array}$ & $\begin{array}{c}-0.57 \\
{[4.85]}\end{array}$ & $\begin{array}{c}2.01 \\
{[4.87]}\end{array}$ & $-22.09 \%$ & & 2173 \\
\hline Gay Male Accountant & $\begin{array}{c}2.43 \\
{[0.80]}\end{array}$ & $\begin{array}{c}-3.58 \\
{[5.02]}\end{array}$ & $\begin{array}{c}-1.15 \\
{[5.01]}\end{array}$ & $-147.33 \%$ & & 2169 \\
\hline Lesbian Accountant & $\begin{array}{c}2.14 \\
{[0.75]}\end{array}$ & $\begin{array}{c}1.18 \\
{[4.76]}\end{array}$ & $\begin{array}{c}3.32 \\
{[4.78]}\end{array}$ & $55.14 \%$ & & 2173 \\
\hline
\end{tabular}

Notes: $n=1859$ in Direct Report condition. Column 1 is the sample mean. Column 2 is the coefficient $\mu$ on "Indirect Report" from a regression with controls. Column 3 adds column 1 and 2, while Column 4 divides Column 2 by Column 1. Standard errors in brackets: Column 2 presents heteroskedasticity-robust standard errors; Standard errors in Column 3 are derived using the bootstrap. Stars indicate significant differences between Indirect Report (Column 2) and Direct Report (Column 1) at levels $* p<.10, * * p<.05$, and $* * * p<.01$ and are labeled in Column 4. Significant differences across occupational contexts can be assessed by examining the standard errors in Column 3 , and can be seen more clearly by examining the error bars in Figure 2. 


\section{Appendices}

\section{APPENDIX A: List Experiment Directions and Statements ${ }^{1}$}

Below is a list of [four/five] things that sometimes make people angry or upset. Please take your time reading the statements below, and then indicate how many make you angry or upset. I don't want to know which ones, just how many: [If Control group, four; if Treatment group, five]

1. A violent criminal recently released from prison winning public office in your district.

2. A Canadian immigrant bagging your food items at your grocery store.

3. A librarian acquiring books that promote atheism for your neighborhood's public library.

4. A person who doesn't believe in evolution creating the course of study for the science department in your district's middle school.

[The Treatment group also received 1 of the following 14 statements, at random:]

5A. A gay male nurse treating you when you are sick in the hospital.

5B. A lesbian nurse treating you when you are sick in the hospital.

5C. A straight (aka, heterosexual) male nurse treating you when you are sick in the hospital.

5D. A gay male elementary school teacher teaching your young children, or young children in your community.

5E. A lesbian elementary school teacher teaching your young children, or young children in your community.

5F. A straight (aka, heterosexual) male elementary school teacher teaching your young children, or young children in your community.

5G. A gay man coaching and training a boys' high school basketball team in your community.

5H. A lesbian coaching and training a girls' high school basketball team in your community

5I. A lesbian mechanic fixing your car engine when you leave your car at the auto repair shop.

5J. A straight (aka, heterosexual) female mechanic fixing your car engine when you leave your car at the auto repair shop.

\footnotetext{
${ }^{1}$ Note that response options and list items were randomized throughout the survey. In other words, the order of the 4 baseline statements were randomized for the control group, and the order of the 4 baseline statements +1 treatment item were randomized for each treatment group. Assignment of the 3 direct questions to the control group after their list experiment were also randomized within gay male conditions, lesbian conditions, and straight conditions.

Additionally, "yes" or "no" response options were randomized in the direct question portion for the control group, but kept the same across questions for each respondent.
} 
5K. A gay male beautician cutting your hair at your next hair appointment. 5L. A straight (aka, heterosexual) male beautician cutting your hair at your next hair appointment.

5M. A gay male accountant doing your tax returns this year. 5N. A lesbian accountant doing your tax returns this year.

How many of the above statements make you angry or upset?

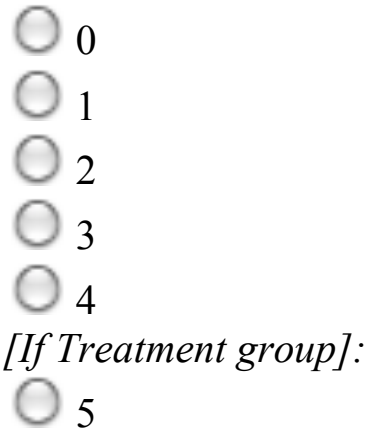

[Immediately after their List Experiment, the Control group was asked 3 of the 14 sensitive statements directly as a question with a Yes/No response about whether the statement "makes them angry or upset." One was a statement about a gay male employee, one about a lesbian employee, and one about a straight employee, in random order. All participants then ended their survey with demographic questions.] 


\section{APPENDIX B: Design Effects Tests}

\begin{tabular}{|l|c|}
\hline \multicolumn{2}{|c|}{$\begin{array}{c}\text { Test for List Experiment } \\
\text { Design Effects }\end{array}$} \\
\hline \multicolumn{1}{|c|}{ Treatment Condition } & $\begin{array}{c}\text { Bonferroni- } \\
\text { corrected p-value }\end{array}$ \\
\hline Gay Male Nurse & $\mathrm{p}=0.28$ \\
\hline Lesbian Nurse & $\mathrm{p}=0.09$ \\
\hline Straight Male Nurse & $\mathrm{p}=0.78$ \\
\hline Gay Male Elem School Teacher & $\mathrm{p}=1.00$ \\
\hline Lesbian Elem School Teacher & $\mathrm{p}=0.49$ \\
\hline Straight Male Elem. Sch. Teacher & $\mathrm{p}=1.00$ \\
\hline Gay Male H.S. Basketball Coach & $\mathrm{p}=0.13$ \\
\hline Lesbian H.S. Basketball Coach & $\mathrm{p}=0.19$ \\
\hline Lesbian Mechanic & $\mathrm{p}=1.00$ \\
\hline Straight Female Mechanic & $\mathrm{p}=0.65$ \\
\hline Gay Male Beautician & $\mathrm{p}=0.39$ \\
\hline Straight Male Beautician & $\mathrm{p}=0.67$ \\
\hline Gay Male Accountant & $\mathrm{p}=0.15$ \\
\hline Lesbian Accountant & $\mathrm{p}=0.39$ \\
\hline
\end{tabular}

Note: If Bonferroni corrected $p$-value is above $p=0.05$, I fail to reject the null hypothesis of no design effect. 